\title{
Dependences and volatility spillovers between the oil and stock markets: New evidence from the copula and VAR-BEKK-GARCH models
}

\author{
Lean $\mathrm{Yu}^{1}$, Rui Zha ${ }^{1}$, Dimitrios Stafylas ${ }^{2}$, Kaijian $\mathrm{He}^{3}$, Jia Liu ${ }^{4 *}$
}

\section{Abstract}

This paper examines the dynamic relationship between the oil market and stock markets from two perspectives: dependence between the crude oil market (WTI) and stock markets of the US and China, and volatility spillovers between them during 1991-2016. We further analyze structural breaks of market dependences and consider the extent of their influence on such relationships. Our vine-copula results show that the dependences between the three paired markets, WTI-US, WTI-China and US-China, vary dynamically across the six identified structural break periods. In particular, the dependence between WTI-US is stronger and more volatile than that between WTI-China during most of the periods. The dependence between US-China remains at a lower level in the earlier periods, but increases in the final period. Our VAR-BEKK-GARCH results demonstrate distinctive volatility spillovers across these periods, with varying directionality, in response to the structural changes. Overall, our results indicate that the oil market stimulates rapid and continual fluctuations in market dependences, which become manifest most acutely in the aftermath of the Financial Crisis of 2007-08, demonstrating the increasing interdependence between the oil and stock markets. Further, the growing influence of China on the dynamics of these relationships, in the period following the Great Recession, presents evidence that it begins to assume an increasingly important role in global economic recovery.

Keywords: Oil market; Stock market; Dependence; Volatility spillover; Copula model; Multivariate GARCH model.

${ }^{1 .}$ School of Economics and Management, Beijing University of Chemical Technology, Beijing 100029, China. Email: yulean@amss.ac.cn (Lean Yu).

School of Economics and Management, Beijing University of Chemical Technology, Beijing 100029, China. Email: 2015200852@mail.buct.edu.cn (Rui Zha).

2. Aston Business School, Aston University, Birmingham, UK. Email: d.stafylas@aston.ac.uk (Dimitrios Stafylas).

${ }^{3 .}$ Hunan Engineering Research Center for Industrial Big Data and Intelligent Decision Making, Hunan University of Science and Technology, Xiangtan 411201, China. Email: kaijian.he@ my.cityu.edu.hk (Kaijian $\mathrm{He}$ ).

${ }^{4}$ Salford Business School, University of Salford, Greater Manchester, UK.

* Corresponding author. Email: j.liu@salford.ac.uk (Jia Liu). 


\section{Dependences and volatility spillovers between the oil and stock markets: New evidence from the copula and VAR-BEKK-GARCH models}

\section{Introduction}

Oil-price volatility has increasingly been the focus of extensive research, as fluctuations in the oil price have generated an unpredictable impact on the trajectory of world oil pricing and, in turn, financial markets (Kang et al., 2015; Wen et al., 2012; Bai and Kai, 2018). Complicating this relationship is the propensity of movements in the stock market to spill over into the oil market, and vice versa. The development of effective techniques to predict market movements, and evaluate the effects of such interactions, is an objective that researchers have long been seeking to achieve (Naifar and Dohaiman, 2013). With the increased complexities of world economies and financial markets, coupled with the growing power of emerging market economies, fluctuations in oil and stock market movements would arguably have even greater endogenous and exogenous consequences for the interactions between the world oil and financial markets. It is with these issues in mind that we examine the dependence between the oil and stock markets and the trajectories of spillovers amongst them, founding our study on West Texas Intermediate (WTI) and the US and China stock markets.

Existing research examines numerous complexities in the relationship between oil prices and equity returns based on statistical regularities of pricing (Hamilton, 2009). Many studies use linear models, such as the vector autoregressive (VAR), to examine the dynamic relationship between the oil and stock markets in respect of their mutual dependence (Antonakakis and Filis, 2013; Arouri et al., 2010; Bjørnland, 2009; Broadstock and Filis, 2014; Filis et al., 2011; Lee and Zeng, 2011; Wang et al., 2013). However, these models have been unable to capture nonlinear aspects of the complex relationship, whether it be dynamically or asymmetrically (tail) dependent.

Recent investigations have employed the time-varying copula model to account for non-linear oil and stock market dynamics. A number of studies demonstrate variously a nonlinear relationship; increased tail dependence among international stock markets (Christoffersen et al., 2012); a dynamic tail dependence exhibited in crude oil prices (Avdulaj and Barunik, 2015); a dynamic dependence between the oil market and stock markets before 
and after the financial crisis (Zhu et al., 2014); and strength of tail dependence and contagion risk in transition economies (Aloui et al., 2013). Although the time-varying copula can determine the dependence between two paired markets, it is not directly applicable when the interactions of multi-markets are the subjects of analysis.

Further studies overcome these limitations by adopting the vine copula model to account for the dependence among markets with high-dimensional complexity. These studies consistently show that this model can effectively capture the dependences among high dimension relationship (Weiß and Supper, 2013; Kraus and Czado, 2017; Allen et al., 2013; Brechmann et al., 2013); while it has also demonstrated superior performance in estimating the nonlinear relationship, including tail dependence (Charpentier and Segers, 2007). Despite these advantages, the vine copula model is unable to ascertain the direction of such dependences.

At the same time, researchers explore price volatility using multivariate GARCH models to facilitate analysis of multi-dimensional relationships among the markets (e.g., Awartani and Maghyereh, 2013; Du and He, 2015; Zhang and Wang, 2014; Jouini, 2013; Sadorsky, 2012). Chuang (2007) and Salisu and Mobolaji (2013) use the VAR-BEKK-GARCH model to analyze the role of volatility spillovers among multi-markets, arguing that this model can produce more accurate forecasts than traditional multivariate GARCH; while some of the traditional GARCH models are limited to modelling extreme cases of risk spillover, such as the GED-GARCH model (Fan, 2008); or require more parameters for estimation, such as the DCC-MECGARCH model (Tsuji, 2018). Further research finds supportive evidence that the VAR-BEKK-GARCH is more efficient, as it requires fewer parameters when analyzing spillovers among several markets (e.g., Schreiber, 2012; Stelzer, 2008; Carpantier and Samkharadze, 2013).

While acknowledging the valuable contribution made by prior research, we contend that shortcomings still remain. First, relationships between and among the markets have become increasingly complicated and multi-dimensional, and early research has been unable to account for dependence and volatility together, to gain a more complete understanding of the nature of underlying risks (Reboredo, 2015; Bekiros and Uddin, 2017; Liu et al., 2017). 
Moreover, most existing studies investigating multi-market dependence relationships have not considered structural breaks and regime changes, which may have stimulated rapid and continually changing volatilities in markets over an extended period of time (e.g., Nguyen, 2012; Sukcharoen et al., 2014; Ji et al., 2018; Zhang, 2017). Even when structural breaks are considered, these studies examine structural breaks in relation to stand-alone markets, rather than dependences between multi-markets that are interacting (e.g., Aloui and Aïssa, 2016), failing to account for structural changes to the interdependence between the markets across temporal subdivisions.

Thus, in our study, we seek to overcome the limitations of earlier researches by examining high-dimensional dependences and risk transmission between the oil and stock markets, and, at the same time, incorporate structural breaks of market dependence into the analysis of such/these relationships. The areas of interest are the crude oil market, West Texas Intermediate (WTI), and two stock markets: the US and China's stock markets. First, we employ the time-varying copula model to examine the dynamics of the relationships among these three markets. Second, to refine our investigation of these relationships still further, we conduct an analysis of structural breaks of the dynamic relationship among the three markets. Our study covers a period of 26 years, during which there have been structural changes caused by significant global events of an economic or political nature. As our focus is on dependences between the three markets, we choose to test and distinguish each structural break in their interdependence, rather than a structural break in each individual market, to account for the nature of regime changes taking place with the power to drive fluctuations in the dynamic relationships. Third, we apply the vine copula model to estimate the dependence relationship between the three paired markets: WTI-US, WTI-China and US-China, across the structural break periods. Fourth, we take one step further to ascertain the direction of such dependences across the temporal subdivisions by examining volatility spillovers between the markets utilizing the trivariate VAR-BEKK-GARCH model.

We choose WTI to represent the oil market because it is one of the foremost global oil markets and is used predominantly as a benchmark in world oil pricing in existing studies (Bekiros and Diks, 2008). We choose the US and China's stock markets for the analysis 
because their economies are the two most powerful and dynamic in the world. The US stock market is the most influential in global financial markets, and China's stock market is also important in its own right, partly because it may act as a surrogate for emerging economies (Liu et al., 2018), and partly because its increasing economic power is likely to exert a considerable influence over world markets in the not-too-distant future (Jiang et al., 2018). We believe that a study of their interactions over a significant length of time is of interest, given the changing dynamics of the US and China in terms of their influence over the global economy, and thereby seek to demonstrate that this gradual transformation is reflected in the dependence and directionality of spillovers. More significantly, the global interdependence of national economies, aggravating the economic consequences of risk contagion between the oil and financial markets, make it imperative to comprehend this complex phenomenon and how it influences the magnitude and trajectory of financial market adjustments and their interactions with the oil market.

Our study derives several significant findings. First, we establish the existence of a dynamic dependence between the oil and stock markets and between the stock markets themselves. Second, our results clearly identify five structural breaks of market dependence, which correspond to dependence volatilities precipitated by significant structural changes of an economic or political nature. Third, our analysis demonstrates that the dependences between the oil market and the two stock markets become stronger, and their tail dependences become more asymmetric with the escalating gravity of regime changes. Among these, the oil market plays a dominant role in these relationships, stimulating rapid and continual fluctuations in market dependences and transmitting information that generates extreme volatilities. The dependence between WTI-US is stronger and more volatile than that between WTI-China during most of these periods. In comparison, the dependence between US-China remains at a lower level in the earlier periods, but increases in the final period, which is evidence of the-increasingly important part that it plays in the ordering of global economics. Fourth, risk volatilities transmit among the three markets dynamically over the six periods in response to economic and political structural changes. Volatility spills unidirectionally from the oil market to the US and China's stock markets, demonstrating that the crude oil market is 
dominant in determining the direction of volatilities between the markets, whose effect becomes manifest most acutely in the aftermath of the Financial Crisis of 2007-08. Risk volatility is transmitted, however, unidirectionally from the US market to China's stock market during the early periods, and turns bidirectional in the final period, providing further evidence that the increasing power of China's stock market is strengthening the financial signals that it transmits.

Our contribution to the literature consists in presenting new evidence of the dependence relationships and spillovers between the oil and stock markets. First, we establish the interdependence and spillovers between the crude oil market and the two most important economies in the world: namely the US and China's markets, over an extended horizon, which has not been explored in previous studies. Second, we introduce structural breaks of market dependence, for the first time, into an analysis of the dependence relationship and risk transmission between the oil and stock markets over a protracted period, incorporating significant political and economic structural changes that may have exerted a transformative effect on the global economy, thus offering a new insight into economic horizon analyses. Third, we construct an evaluation procedure for measuring and analyzing dependence and spillovers between oil and stock markets by means of the vine copula model and multivariate (trivariate) GARCH model, accounting for their connection with changing structural regimes. Our evaluation procedure has value for both practice and policy alike, aiding governments, market-makers and investors in the examination of similar phenomena in other countries and contexts. From a policy perspective, this lens provides a vital focus for policy-makers, enabling them to perceive the dynamic interactions of powerful markets and how these may impact upon other regions of the world, and meanwhile empower them to develop strategies to encourage long-term, maintainable economic growth. The insights gained from the investigation into the dynamics of interdependence between WTI, US and China may be fruitfully applied to other economies, their national idiosyncrasies notwithstanding. From a practice perspective, our research will enable investors to identify the causes and trajectories of volatilities and manage the investment risk and efficiency of their portfolios at a time of increasing global market instability. 
The rest of the paper is organized as follows. Section 2 discusses the methods, including the time-varying copula model, vine copula model and multivariate GARCH model, as well as structural break tests. Section 3 discusses the data and sample. Section 4 presents and discusses the empirical results. Section 5 summarizes our main findings and considers policy and practical implications.

\section{Modelling framework}

We proceed in four steps. First, we adopt the time-varying copula model for estimating the dynamic dependence relationship between the crude oil market and stock markets in the US and China. Second, major economic and political events have occurred during our extended period of study, which may have impacted upon the relationships among the markets. To account for structural changes, we identify what we term the structural break of market dependence, precipitated by economic or political events, and examine the dependence and spillovers between the paired markets over each of the identified temporal subdivisions. Third, we consider the dependence between the three paired markets: WTI-US, WTI-China and US-China, in each period that we identify, by applying the vine copula model. The latter has an ability to estimate high-dimensional dependence and tail dependence among different markets, and can capture the nonlinear relationship in multi-markets. During this process, we also identify the root nodes for each period, facilitating our examination of how the risk information is received and disseminated in the course of market interactions. Fourth, we adopt the VAR-BEKK-GARCH model to examine if, and how, volatility spills across these markets and periods, and employ the Wald test to determine the direction of the spillover effect between the markets.

\subsection{Estimation of the marginal distribution}

It is established that oil and financial data is characterized by fat tail and high kurtosis (Bauwens and Lubrano, 2002; Ghose and Kroner, 1995). The GARCH model has the ability to match fat tail and high kurtosis characteristics of data, and, thus, can be used to compute marginal distribution in order to transform oil and stock price data to make it suitable for estimation by the copula models. We adopt the Glosten-Jagannathan-Runkle $\operatorname{GARCH}(1,1)$ 
model (GJR-GARCH $(1,1)$ for short), and combine it with the $\operatorname{AR}(1)$, on the basis that the $\operatorname{AR}(1)-G J R-G A R C H(1,1)$ model is suitable for estimating the marginal distribution (Aloui et al., 2013). In this way, our estimations can better capture non-linear features of oil price and stock price, and ensure an accurate estimation of the time-varying copula model and vine copula model. Given that the standardized residual follows the skewed student-t distribution, the model of AR(1)-GJR-GARCH(1, 1) is given below.

$$
\begin{aligned}
& r_{t}=\mu+\beta r_{t-1}+\varepsilon_{t} \\
& \sigma_{t}^{2}=\alpha+\phi \varepsilon_{t-1}^{2}+\varphi \sigma_{t-1}^{2}+\gamma K_{t-1} \varepsilon_{t-1}^{2} \\
& \varepsilon_{t}=\sigma_{t} e_{t} \\
& e_{t} \sim \text { skewed student }-t(\chi, \eta)
\end{aligned}
$$

where $r_{t}$ is the return of market price, which is derived by using $r_{t}=\ln p_{t+1}-\ln p_{t}$, where $p_{t}$ is the price of WTI, US stock market and China's stock market at time t. $\sigma_{t}$ and $\varepsilon_{t}$ represent the conditional volatility and the residual, respectively; and $e_{t}$ is the standardized residual and follows the skewed student-t distribution. Skewed student-t distribution can capture the excess kurtosis and skewness, and is, therefore, better fitted with the real data than the normal distribution. $K_{t-l}$ captures the leverage effect of the residual. When the residual, $\varepsilon_{t}$, is positive, $K_{t-1}$ equal to 0 ; and $K_{t-1}$ equal to 1 when the residual, $\varepsilon_{t}$, is negative.

After these procedures, oil and stock market price characterizing fat tail and high kurtosis will be transformed into data that follows a uniform distribution within $[0,1]$, which are suitable for estimation by the copula models.

\subsection{Time-varying copula model}

To examine the dynamic relationship between each paired market, we adopt the time-varying copula model. Both the Clayton copula model (Clayton, 1978) and symmetrized Joe-Clayton (SJC) copula model (Patton, 2006) have the ability to address tail dependence in the financial data. The two models differ in respect of tail dependence. The Clayton copula model deals with lower tail dependence, while the SJC copula model deals with both upper and lower dependence. The Clayton copula model is defined below.

$C_{\text {Clayton }}\left(u_{1}, u_{2} \mid \varepsilon\right)=\left(u_{1}^{-\varepsilon}+u_{2}^{-\varepsilon}-1\right)^{-1 / \varepsilon}$ 
where $\varepsilon \in(0, \infty)$. $\varepsilon$ is the parameter of the Clayton copula model; $u_{1}$ and $u_{2}$ are two variables.

The SJC copula model is an extension of the Clayton copula model. It is specified below.

$$
C_{S J C}\left(u_{1}, u_{2} \mid \lambda^{U}, \lambda^{L}\right)=0.5 \cdot\left(C_{J C}\left(u_{1}, u_{2} \mid \lambda^{U}, \lambda^{L}\right)+C_{J C}\left(1-u_{1}, 1-u_{2} \mid \lambda^{L}, \lambda^{U}\right)+u_{1}+u_{2}-1\right)
$$

where $\lambda^{U}$ and $\lambda^{L}$ represent parameters of upper and lower tail dependence, $\lambda^{U} \in(0,1), \lambda^{L} \in(0,1)$, respectively. $C_{J C}$ is the Joe-Clayton copula model, which is defined below.

$$
C_{J C}\left(u_{1}, u_{2} \mid \lambda^{U}, \lambda^{L}\right)=1-\left(1-\left\{\left[1-\left(1-u_{1}\right)^{\alpha}\right]^{-\beta}+\left[1-\left(1-u_{2}\right)^{\alpha}\right]^{-\beta}-1\right\}^{-1 / \alpha}\right)^{1 / \beta}
$$

where $\alpha=1 / \log _{2}\left(2-\lambda^{U}\right)$ and $\beta=-1 / \log _{2}\left(\lambda^{L}\right)$.

Both the Clayton copula and the SJC copula models can model tail dependence between the three paired markets using Eqs. (2) and (3). We adopt the Akaike Information Criterion (AIC), Bayesian Information Criterion (BIC), and Log-likelihood to determine a better copula model for our analysis, which will be applied to examine dynamic dependence relationships between the paired markets.

The dynamic Kendall's $\tau$ is to measure the time-varying dependence relationship between each paired market. Kendall's $\tau$ of the Clayton copula model is estimated below.

$$
\tau_{\text {Clayton }, t}=\Lambda\left(\delta+\phi \tau_{\text {Clayton }, t-1}+\alpha\left|u_{1, t-1}-u_{2, t-1}\right|\right)
$$

where $\delta$ is the constant; and $\phi$ and $\alpha$ are the parameters.

Different from the Clayton copula model, the SJC copula model is composed of both upper and lower Kendall's $\tau$, which can be estimated by Eqs. (6) and (7) below, respectively.

$$
\begin{aligned}
& \tau_{U, t}=\Lambda\left(\delta_{U}+\phi_{U} \tau_{U, t-1}+\alpha_{U} \frac{1}{10} \sum_{i=1}^{10}\left|u_{1, t-i}-u_{2, t-i}\right|\right) \\
& \tau_{L, t}=\Lambda\left(\delta_{L}+\phi_{L} \tau_{L, t-1}+\alpha_{L} \frac{1}{10} \sum_{i=1}^{10}\left|u_{1, t-i}-u_{2, t-i}\right|\right)
\end{aligned}
$$

where $\Lambda$ is a function with $\Lambda(x)=\left(1+e^{-x}\right)^{-1}$ and is used to maintain Kendall's $\tau$ within $(0,1)$; $\delta_{U}$ and $\delta_{L}$ are the constant parameters of upper and lower Kendall's $\tau ; \phi_{U}, \alpha_{U}, \phi_{L}$ and $\alpha_{L}$ are the parameters of upper and lower Kendall's $\tau$. $\tau_{U, t}$ and $\tau_{L, t}$ follow the ARMA $(1,10)$ as specified in Eqs. (6) and (7), respectively, and represent the upper and lower tail dependence relationship (Patton, 2006). 


\subsection{Structural break}

Based on the dynamic dependence relationship between the oil and stock markets, we consider if there are structural breaks of the dependence relationship between these markets over a 26-year horizon. During our study period, some major economic and political events occurred, such as the first Gulf War of 1991, the Iraq War of 2003, the September $11^{\text {th }}$ attack of 2001, and the financial crisis of 2007-08. As our focus is on the dependences between the three markets, we choose to test the structural breaks of the dependence between them, rather than a structural break in each individual market. Analyses based on an individual market cannot be extrapolated to capture the dependence between markets. By analyzing structural breaks of dynamic dependence among multiple markets, we are able to account for the stability of market interdependence in such relationships.

The Chow and BP structural break tests are widely used in empirical analyses. The Chow test (Chow, 1960) is applicable when the structural break date is known. The BP test, proposed by Bai and Perron (1998), has an advantage, in that it can test for multiple unknown breakpoints (Prodan, 2008; Aloui and Aïssa, 2016; Carrion-I-Silvestre, 2005). As our study covers an extended period, there may be a series of unknown structural breakpoints. Therefore, we employ the BP test to identify structural breaks of the dynamic relationships between each paired market. For $t$ periods and $n$ breakpoints, the linear regression model for the BP test is specified below.

$$
y_{t}=x_{t} \alpha+z_{t} \beta_{j}+\varepsilon_{t}
$$

where $j$ represents the structural regimes and $j=0, \ldots, n ; x_{t}$ represents variables that do not vary across the structural regimes; $z_{t}$ represents variables that have coefficients corresponding to their individual structural regime. Through comparing estimated values of these two groups with the true values, the breakpoints can be identified. We will then incorporate the structural breaks, which we term the structural break of the market dependence, into the examination of the dependence between the three markets by applying the vine copula model, and the spillovers between them by applying the VAR-BEKK-GARCH model. 


\subsection{Vine copula model}

The vine copula model is an extension of the time-varying copula model and is introduced to examine dependence among markets with high-dimensional complexity by Joe (1997) and Aas (2009). The vine copula model has the ability to analyze high dimensional dependence relationships among three markets or more. When more markets are included in the analysis, they interact with one another, so that the network of dependence relationships among them becomes increasingly complex. As a consequence, the parameters to be estimated increase exponentially. Clearly, modelling the interrelationships of the three-market networks in our study requires the application of the vine copula model.

The vine copula model uses a set of bivariate copula models and marginal density function to investigate high-dimensional dependence relationship. Two main vine copula models, C-vine copula and D-vine copula, have been used widely to analyze multi-dimensional dependence. For $n$-dimension dependence, the C-vine copula and D-vine copula models are specified below.

C-vine copula model:

$$
\begin{aligned}
f\left(u_{1}, \ldots, u_{n}\right)= & \prod_{i=1}^{n} f\left(u_{i}\right) \prod_{g=1}^{n-1} \prod_{k=1}^{n-g} c_{g}, g+k \mid 1, \ldots, g-1 \\
& {\left[F\left(u_{g} \mid u_{1}, \ldots, u_{g}-1\right), F\left(u_{g}+k \mid u_{1}, \ldots, u_{g-1}\right)\right] }
\end{aligned}
$$

D-vine copula model:

$$
\begin{aligned}
f\left(u_{1}, \ldots, u_{n}\right)= & \prod_{i=1}^{n} f\left(u_{i}\right) \prod_{g=1}^{n-1} \prod_{k=1}^{n-g} c_{g}, g+k \mid k+1, \ldots, k+g-1 \\
& {\left[F\left(u_{k} \mid u_{k+1}, \ldots, u_{k+g-1}\right), F\left(u_{g}+k \mid u_{k+1}, \ldots, u_{k+g-1}\right)\right] }
\end{aligned}
$$

where $f\left(u_{1}, \ldots, u_{n}\right)$ is the joint density function; $c$ represents any type of the copula models; $F$ is the marginal distribution function; $n$ is the dimension; $g$ is the tree; and $i$ is the edge of the tree.

For the $n$-dimensional dependence, the density function can be decomposed into $n(n-1) / 2$ pairs-copula models and $n$ marginal density functions. In our study, there are three markets, i.e., $n=3$. When the number of variables is three, the $\mathrm{C}$-vine copula and $\mathrm{D}$-vine copula models have a common function (Aas, 2009), which is specified below. 


$$
\begin{aligned}
f\left(u_{1}, u_{2}, u_{3}\right)= & f\left(u_{1}\right) \cdot f\left(u_{2}\right) \cdot f\left(u_{3}\right) \\
& \cdot c_{12}\left[F\left(u_{1}\right), F\left(u_{2}\right)\right] \cdot c_{23}\left[F\left(u_{2}\right), F\left(u_{3}\right)\right] \\
& \left.\cdot c_{13}\right|_{2}\left[F\left(u_{1} \mid u_{2}\right), F\left(u_{3} \mid u_{2}\right)\right]
\end{aligned}
$$

As we examine the three markets in our study, the C-vine copula and D-vine copula models have two trees and three edges, i.e., $n=3$, accordingly. Thus, both models have a common function for estimation. We, therefore, adopt the three-dimensional C-vine copula model, for convenience, to estimate the dependence relationship among the three paired markets.

\subsection{VAR-BEKK-GARCH model}

As shown, the vine copula model can only estimate the dependence relationship between the markets. The direction of their dependence, such as spillovers of risk volatility from one market to another, cannot be deduced from the copula models directly. To resolve this, we adopt the trivariate VAR-BEKK-GARCH model, which is able to ascertain the direction of volatility spillovers between multi-markets. The VAR-BEKK-GARCH model, a multivariate GARCH model proposed by Engle and Kroner (1995), estimates the conditional mean function and the conditional volatility function of high-dimensional relationships, which we use to test volatility spillovers between multi-markets. We add VAR (1) into the conditional mean function, Eq. 12, to improve the accuracy of our forecasts, as suggested by Jayasinghe et al (2014) and Mensi et al (2014). The $\operatorname{VAR}(1)-\operatorname{BEKK}-\operatorname{GARCH}(1,1)$ model is thus specified below.

$$
\begin{aligned}
& R_{\mathrm{t}}=\mu+\alpha R_{\mathrm{t}-1}+\varepsilon_{\mathrm{t}} \\
& \varepsilon_{t} \sim N\left(\mathrm{O}, H_{t}\right) \\
& \mathrm{H}_{\mathrm{t}}=\mathrm{CC}^{\prime}+\mathrm{DH}_{\mathrm{t}-1} \mathrm{D}^{\prime}+\mathrm{A}\left(\varepsilon_{\mathrm{t}-1} \varepsilon_{\mathrm{t}-1^{\prime}}\right) \mathrm{A}^{\prime}
\end{aligned}
$$

where $R_{t}$ is the returns matrix of the oil and stock markets; $\mu$ is a $3 \times 1$ vector of constant; and $\varepsilon_{t}$ is a $3 \times 1$ vector of the residual and follows a normal distribution, in which the mean is zero. $H_{t}$ is the conditional variance-covariance matrix. $C$ is a constant matrix and $3 \times 3$ lower triangular 
vector, where the constant, $c_{i j}$, is included. $D$ is a $3 \times 3$ parameter matrix of conditional variance, where $d_{i j}$ represents the relation of the conditional variance between market $i$ and market $j$. $A$ is a $3 \times 3$ parameter matrix of residual, where $a_{i j}$ is included to capture the $\mathrm{ARCH}$ effect in the residual in market $i$ and market $j$. To test the volatility spillover effect, we use the Wald test to test the null hypothesis that if the difference of $A$ and $D$ equals zero. For market $i$ and market $j$, the Wald test hypothesize that $\mathrm{A}(i, j)=\mathrm{D}(i, j)=0$. The rejection of the null hypothesis indicates that the risk spills over from market $i$ to market $j$.

\section{Data and basic statistics}

\subsection{Data and sample}

We employ the daily crude oil future price of West Texas Intermediate and two stock market indices: the Dow Jones Industrial Average (DJI) and the Shanghai Composite Index (SHCI), which represent the stock markets of the US and China, respectively. We use the SHCI for China because it is the first index adopted by China's stock market. Although the SHCI had its inception on December 19, 1990, we make use of the full range of datasets that were made available from the Wind database at the time when this research was conducted. WTI's oil future closing prices are obtained from the US Energy Information Agency. Crude oil futures contracts are reported in detail on the EIA website (https://www.eia.gov/). The DJI and SHCI data are collected from the Wind database (http://www.wind.com.cn/en/). The dataset has 5877 observations from the 2 May 1991 to 31 May 2016, excluding holidays, weekends and any other non-trading days.

\subsection{Descriptive statistics}

Table 1 reports the descriptive statistics and ARCH-LM test statistics for the marginal distribution of the returns of the three markets. The mean value of all returns is close to zero, and values of skewness $(-0.2041,-0.2275,5.1944)$ and kurtosis $(5.3393,9.3743,135.5430)$ appear to be a departure from the normal distribution, given that the skewness and kurtosis of the normal distribution should be 0 and 3 , respectively. These statistics indicate that the returns of the three markets are characterized by fat tails. Additionally, the Jarque-Bera test rejects the null hypothesis, indicating that the returns do not follow the normal distribution. These results confirm that there is the ARCH effect in the oil price and stock market returns. 
Hence, we adopt the GARCH model (AR(1)-GJR-GARCH $(1,1)$-Skew- $t$ model) to account for the ARCH effect exhibited in the three market returns.

Table 1. Descriptive statistics of daily returns of the oil and stock markets

\begin{tabular}{lllllllll}
\hline & Mean & Variance & Min & Max & Skewness & Kurtosis & Jarque-Bera test & ARCH-LM (10) \\
\hline WTI & 0.0001 & 0.0006 & -0.1966 & 0.1641 & -0.2041 & 5.3393 & $7028^{* * *}$ & $675.7000^{* * * *}$ \\
US & 0.0003 & 0.0001 & -0.1127 & 0.1051 & -0.2275 & 9.3743 & $21586^{* * *}$ & $1308.5000^{* * * *}$ \\
China & 0.0005 & 0.0006 & -0.1791 & 0.7192 & 5.1944 & 135.5430 & $4527600^{* * *}$ & $27.2980^{* * *}$ \\
\hline
\end{tabular}

Notes. Table 1 reports the summary statistics of the daily returns of the oil market, the US stock market and China's stock market. The Jarque-Bera test is for testing normality of oil price and market returns. The ARCH-LM (10) is the Lagrange Multiple test for the autoregressive conditional heteroscedasticity, with the degree of freedom $=10 .{ }^{* * *},{ }^{* *}$ and ${ }^{*}$ indicate confidence levels at $1 \%, 5 \%$ and $10 \%$, respectively.

\section{Empirical results and discussions}

\subsection{Marginal distributions of market returns}

Table 2 reports the estimated results of the marginal distribution of market returns. The results show that most of the parameters in the GARCH model are statistically significant. Especially, the kurtosis parameters, $\chi$, and asymmetry parameters, $\eta$, of the three residual series are both statistically significant. These results indicate that the market returns for our analyses are characterized by fat tail and are asymmetrical, providing supportive evidence that linear models with normal distribution are inappropriate for estimating the relationships among the three markets.

Table 2. Estimation results of marginal distribution of market returns of the oil market, the US stock market and China's stock market

\begin{tabular}{llll}
\hline & WTI & US & China \\
\hline$\mu$ & 0.0000 & $0.0003^{* * * *}$ & $0.0006^{* * *}$ \\
$\beta$ & $(0.0002)$ & $(0.0001)$ & $(0.0002)$ \\
& $-0.0289^{* *}$ & -0.0280 & $0.0373^{* *}$ \\
$\alpha$ & $(0.0116)$ & $(0.0202)$ & $(0.0150)$ \\
& $0.0000^{* * *}$ & $0.0000^{* * *}$ & $0.0000^{* * *}$ \\
$\phi$ & $(0.0000)$ & $(0.0000)$ & $(0.0000)$ \\
& $0.0239^{* * *}$ & 0.0000 & $0.0946^{* * *}$ \\
$\varphi$ & $(0.0056)$ & $(0.0219)$ & $(0.0184)$ \\
& $0.9577^{* * * *}$ & $0.9152^{* * *}$ & $0.8647^{* * *}$ \\
& $(0.0049)$ & $(0.0237)$ & $(0.0223)$
\end{tabular}




\begin{tabular}{llll}
$\gamma$ & $0.0321^{* * *}$ & $0.1407^{* * *}$ & $0.0715^{* * *}$ \\
$\chi$ & $(0.0085)$ & $(0.0180)$ & $(0.0210)$ \\
& $6.2941^{* * *}$ & $6.5226^{* * *}$ & $3.9832^{* * *}$ \\
$\eta$ & $(0.5351)$ & $(0.5958)$ & $(0.2406)$ \\
& $-0.0691^{* * *}$ & $-0.0880^{* * *}$ & $-0.0300^{* *}$ \\
& $(0.0210)$ & $(0.0229)$ & $(0.0139)$ \\
\hline
\end{tabular}

Notes: Table 2 reports the estimation results of the marginal distribution of the market returns of the oil market, the US stock market and China's stock market based on the GARCH model in Equation 1. The standard errors are in the parentheses. $\mu$ and $\beta$ are the parameters of the conditional mean function. $\alpha, \phi, \varphi$ and $\gamma$ are the parameters of the conditional variance function; $\chi$ and $\eta$ represent the kurtosis parameter and asymmetry parameter of the residuals, respectively. ${ }^{* * *},{ }^{* *}$ and ${ }^{*}$ indicate confidence levels at $1 \%, 5 \%$ and $10 \%$, respectively.

\subsection{Dynamic dependence relationships by time-varying copula model: results and discussions}

To capture the dynamic relationship between the three paired markets, we proceed in two steps. First, we estimate the time-varying Clayton copula and the time-varying SJC copula models to establish the dynamic relationship between the paired markets based on Eq. 2 and Eq. 3. Second, we choose better-fitted copula models, basing our selection on the criteria that the structural breaks are determined by the smallest values of AIC and BIC, and also by the largest values of Log-likelihood. The AIC, BIC and Log-likelihood results of the two time-varying copula models are reported in Table 3.

Table 3 shows that for WTI-China, the AIC, BIC and Log-likelihood are at -5.3931, 14.6428 and 5.6966 from the time-varying Clayton copula model, respectively; and at 2.5649, 42.6367 and 4.7176 from the time-varying SJC copula model, respectively. For US-China, the AIC, BIC and Log-likelihood are at 0.1649, 20.2008 and 2.9175 from the time-varying Clayton copula model, respectively, and at $14.0493,54.1211$ and -1.0246 from the time-varying SJC copula model, respectively. These results indicate that the time-varying Clayton copula model performs better than the time-varying SJC copula model for the paired markets of WTI-China and US-China. For WTI-US, the AIC and Log-likelihood are at -270.4411 and 138.2250 from the time-varying Clayton copula model and -280.0522 and 146.0261 from the time-varying SJC copula model, indicating that there is not much difference between the two copula models in terms of model performance. Given the above, we adopt the time-varying Clayton copula model for our dependence analyses. 
Table 3. Estimation results of the time-varying Clayton and SJC copula models for the three paired markets

\begin{tabular}{|c|c|c|c|}
\hline & WTI-US & WTI-China & US-China \\
\hline \multicolumn{4}{|c|}{ Time-varying Clayton copula model } \\
\hline \multirow[t]{2}{*}{$\sigma$} & $0.1013^{* * *}$ & -4.4400 & $-10.0000^{* * * *}$ \\
\hline & $(0.0235)$ & $(3.3568)$ & $(0.0002)$ \\
\hline \multirow[t]{2}{*}{$\phi$} & $-0.5285^{* * * *}$ & -1.8336 & $4.8224^{* * *}$ \\
\hline & $(0.1295)$ & $(2.5059)$ & $(1.4361)$ \\
\hline \multirow[t]{2}{*}{$a$} & $0.9778^{* * * *}$ & -0.3677 & $-0.5081^{* * *}$ \\
\hline & $(0.0060)$ & $(0.8049)$ & $(0.1516)$ \\
\hline AIC & -270.4411 & -5.3931 & 0.1649 \\
\hline $\mathrm{BIC}$ & -250.4052 & 14.6428 & 20.2008 \\
\hline Log-likelihood & 138.2250 & 5.6966 & 2.9175 \\
\hline \multicolumn{4}{|c|}{ Time-varying SJC copula model } \\
\hline \multirow[t]{2}{*}{$\sigma_{U}$} & 1.5926 & $-0.7272^{* * *}$ & $-7.1650^{* * * *}$ \\
\hline & $(1.8995)$ & $(0.0000)$ & $(2.7463)$ \\
\hline \multirow[t]{2}{*}{$\phi_{U}$} & -9.9999 & $-0.2534^{* * *}$ & -1.9781 \\
\hline & $(13.4900)$ & $(0.0028)$ & $(3.1897)$ \\
\hline \multirow[t]{2}{*}{$\alpha_{U}$} & $0.7421^{*}$ & $1.8095^{* * *}$ & $8.4088^{* * *}$ \\
\hline & $(0.3981)$ & $(0.0000)$ & $(2.3386)$ \\
\hline \multirow[t]{2}{*}{$\sigma_{L}$} & $0.1715^{* * *}$ & -0.4762 & $-5.7303^{* * *}$ \\
\hline & $(0.0477)$ & (18.6707) & (2.1037) \\
\hline \multirow[t]{2}{*}{$\phi_{L}$} & $-0.7954^{* * *}$ & -0.3621 & -1.7138 \\
\hline & $(0.2285)$ & $(61.9643)$ & $(8.0599)$ \\
\hline \multirow[t]{2}{*}{$\alpha_{L}$} & $0.9812^{* * *}$ & 1.1415 & $6.9297^{* * *}$ \\
\hline & $(0.0058)$ & $(1.2150)$ & $(1.8283)$ \\
\hline AIC & -280.0522 & 2.5649 & 14.0493 \\
\hline $\mathrm{BIC}$ & -239.9804 & 42.6367 & 54.1211 \\
\hline Log-likelihood & 146.0261 & 4.7176 & -1.0246 \\
\hline
\end{tabular}

Notes. Table 3 reports the estimation results of estimations of the time-varying Clayton and SJC copula models. $\sigma, \phi$ and $\alpha$ are the parameters of the time-varying Clayton copula model. $\sigma_{U}, \phi_{U}$ and $\alpha_{U}$ are the parameters of the upper tail in the time-varying SJC copula model, and $\sigma_{L}, \phi_{L}$ and $\alpha_{L}$ are the parameters of the lower tail in the time-varying SJC copula model. Standard errors of parameters are reported in parentheses. ${ }^{* * * * *}$ and ${ }^{*}$ indicate confidence levels at $1 \%, 5 \%$ and $10 \%$, respectively.

\subsection{Structural break analysis: results and discussions}

Figures 1-3 present the results of the BP test for the structural breaks of the market dependences, measured by Kendall's $\tau$ estimated by the time-varying copula model. The Schwarz Criterion is used to determine the number of breakpoints for each paired market.

As shown in Figure 1, there are distinct fluctuations in the dynamic dependence 
relationship between the oil price and the Dow Jones index across the six structural break periods. Specifically, we have identified five breakpoints in the paired WTI-US dependence, based on the Schwarz Criterion when it is at the lowest value $(=-6.1024)$ at the $5 \%$ level of significance. These five breakpoints are: 7 October 1993, 5 November 2002, 19 October 2006, 17 April 2009, and 18 April 2013. During the first four break periods, the dependence fluctuates within the range of $0-0.11$. Subsequently, the dependence fluctuates more radically, displaying intensified volatilities over the last two periods. Most notably, during the period from 17 April 2009 to 18 April 2013, the fluctuation ranges from 0.05 to 0.50 , demonstrating that the Financial Crisis of 2017-18 and the Great Recession that follows generate a marked effect on the dependence between the oil market and the US stock market. The dependence rises to the highest level throughout 2008-2013 and also demonstrates fluctuations of a high magnitude. The overall results show that the dependence between the crude oil market and the US stock market has grown stronger than ever in the aftermath of the global financial crash, providing us with an insight into how sensitively the market dependence responds to such extreme financial oscillations.

Figure 1. Structural breaks of dynamic dependence between WTI and the US stock market

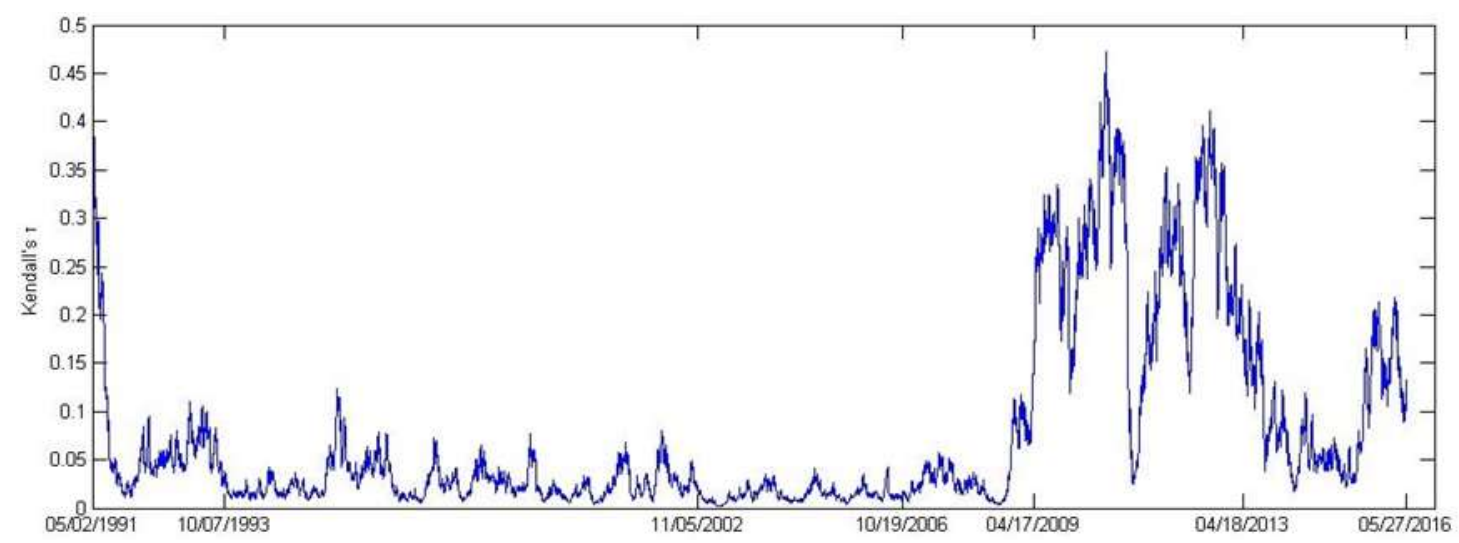

Notes. Figure 1 presents the dynamic dependence relationship between WTI and the US stock market. The horizontal axis indicates the dates of the structural breaks of dynamic dependence between WTI and the US stock market based on the BP test, and the vertical axis indicates Kendall's $\tau$, which represents the strength of dynamic dependence between the two markets.

Figure 2 shows that the dependence between WTI and the Shanghai Composite Index fluctuates within the range of $0.005-0.06$. By the BP test, the Schwarz Criterion is the 
smallest (-9.6009) when the number of breakpoints is zero, and when the number of breakpoints is one, the Schwarz Criterion is the second smallest (-9.5992). There is less evidential support for distinctive structural breaks of the dependence relationship between WTI and China's stock market.

Figure 2. Structural breaks of dynamic dependence between WTI and China's stock market

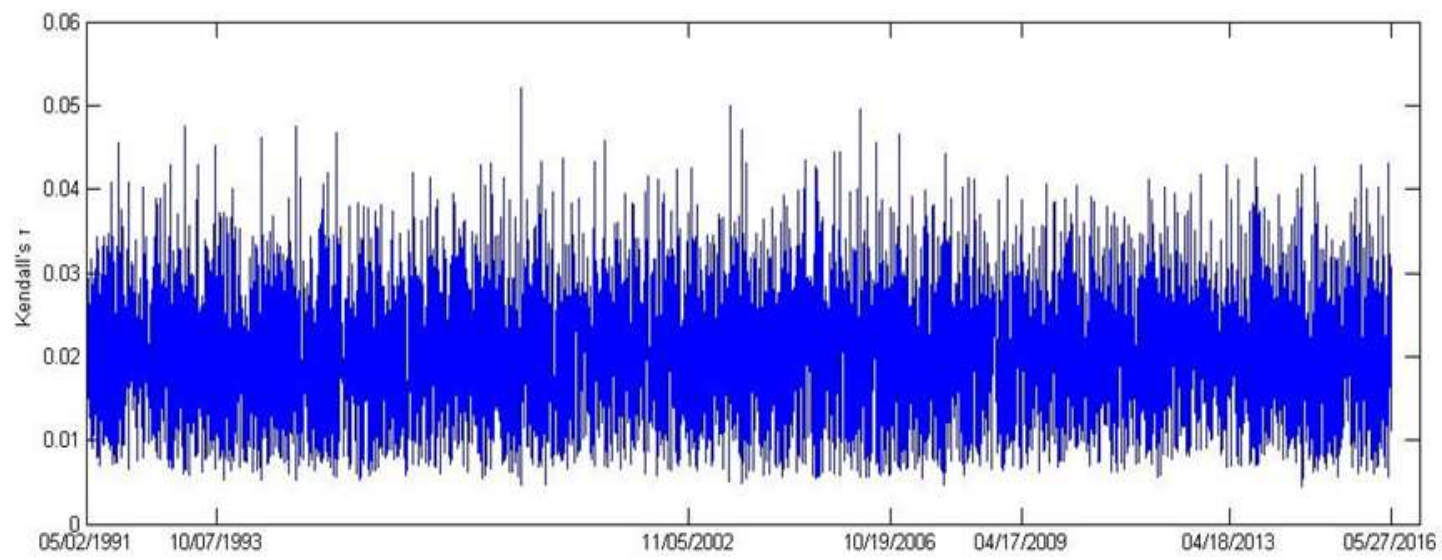

Notes. Figure 2 presents the dynamic dependence relationship between WTI and China's stock market. The horizontal axis indicates the dates of the structural breaks of dynamic dependence between WTI and China's stock market based on the BP test, and the vertical axis indicates Kendall's $\tau$, which represents the strength of dynamic dependence between the two markets.

The dynamic dependence between the US and China's stock markets is sustained at the lowest level throughout these periods, as depicted in Figure 3. The dependence fluctuates within the range of $0-0.14$ in most observations. By the BP test, the Schwarz Criterion is the smallest (-8.8649) when the number of breakpoints is zero. When the number of breakpoints is one, the Schwarz Criterion is the second-smallest (-8.8627). These statistics show that the dependence relationship is relatively stable between the US and China's stock markets in comparison to WTI and the US stock market.

Figure 3. Structural breaks of dynamic dependence between the US and China's stock markets 


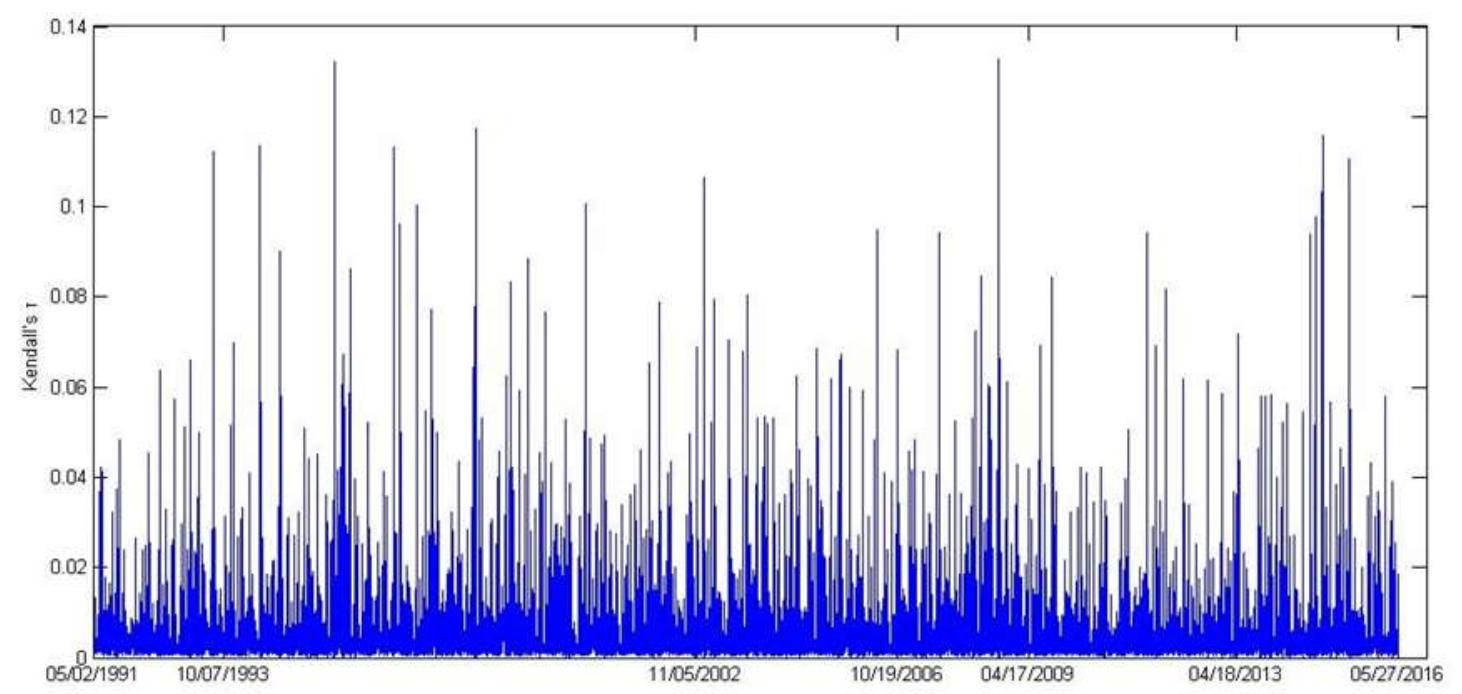

Notes. Figure 3 presents the dynamic dependence relationship between the US and China's stock market. The horizontal axis indicates the dates of the structural breaks of dynamic dependence between the US and China's stock market based on the BP test, and the vertical axis indicates Kendall's $\tau$, which represents the strength of dynamic dependence between the two markets.

Overall, our results show that the dependence between WTI-US is much more volatile than that between WTI-China, while the US-China dependence is fairly stable. As the five structural breakpoints identified for WTI-US incorporate transformative events, influencing the global economy through these periods, it is to be expected that the stability of the oil and stock markets will be significantly affected across all the three paired markets. We thus apply the same structural breaks to WTI-China and US-China, so as to facilitate consistent comparisons based uniformly on the same periods. Therefore, we adopt the five structural breaks of the market dependence to determine the dependence and directionality of spillovers between the three paired markets. Based on these five breakpoints, we divide our data into the six periods as depicted in Figure 1: P1: 2 May 1991 to 7 October 1993; P2: 7 October 1993 to 5 November 2002; P3: 5 November 2002 to 19 October 2006; P4:19 October 2006 to 17 April 2009; P5:17 April 2009 to 18 April 2013; and P6:18 April 2013 to 31 May 2016.

The foregoing analysis suggests that the generation of these breakpoints has resulted from economic stimuli. For example, the outbreak of wars in oil-producing countries affects the oil supply, which, in turn, is likely to increase the volatility of stock markets; while the shock of a financial crisis can render the latter even more unstable. A political crisis, possibly 
resulting in a radical change of regime, can have similar, destabilizing effects. As the timeline of Figure 1 shows, the extended period of our study incorporates a series of such destabilizing events, not the least of which is the Financial Crisis of 2007-08, and we are confident that our analysis has identified the significant breakpoints, which correspond to dependence volatilities precipitated by changes in response to the political and economic events that occur. We will consider the impact of these structural breaks in detail in Sections 4.4 and 4.5.

So far, we have examined the dynamic dependence of the three paired markets, based on the time-varying copula model, over the six structural periods. However, the time-varying copula model can deal with only one paired market, without the power to estimate the dependence when all the three paired markets interact simultaneously. In order to facilitate an examination of the multi-market dependences, we thus employ the vine copula model.

\subsection{Market dependence by vine copula model: results and discussions}

As is known, the vine-copula model has more than 30 different types. We choose the best-fitted copula models based on the AIC and BIC criteria. When the upper tail is equal to the lower tail, the tail dependence is symmetrical; otherwise, it is asymmetrical, which indicates that tail dependences are strong when extreme risk occurs. Based on Kendall's $\tau$ for measuring strength of dependence, as in Eq. 11, the following copula models are selected: Student- $t$, Rotated Tawntype 2 (270 degrees), Rotated BB7 (90 degrees) and Rotated BB8 (90 degrees), for estimating symmetrical tail dependence; and Clayton, Tawntype 1, BB7, BB1, and Gumbel, for estimating asymmetrical tail dependence (see Joe et al., 2010; Brechmann et al., 2013, for detail). The results of the vine copula model estimations are reported in Table 4.

Our results demonstrate that the dependences among the three markets undergo dynamic shifts through the six periods in response to the political and economic events that occur. In the periods of P1, P4 and P5, the crude oil market is identified as the root node, demonstrating that it is at the nexus of the dependence relationships between the three paired markets during these phases. It appears that the dependences of WTI-US, WTI-China and US-China increase from 0.03, - 0.04 and 0.00 in P1 to 0.04, 0.04 and 0.02 in P4, and then to 0.34, 0.13 and 0.02 in P5, respectively, indicating that the dependences among the three markets grows stronger over the periods. The dependence manifests itself in the trajectory of 
a series of significant events that occur within these breaks. In P1, the Gulf War breaks out, with an invasion of Kuwait that threatens to restrict world oil supplies. P4 incorporates adverse developments following the Iraq War and, in particular, the onset of the Financial Crisis of 2007-08, both of which arguably have a significant impact on oil prices (Silvapulle et al., 2017; Bhar and Malliaris, 2011). This is consistent with the surging volatilities observed in P4 as depicted in Figure 1. In P5, the dependence between WTI-US and WTI-China remains at the highest levels (Kendall's $\tau=0.34$ and 0.13 , respectively). The onset of the global financial crisis in 2007-08 produces the most extreme volatility of all breakpoints, as recorded in Figure 1, and this is further intensified in P5 by the European Debt Crisis and the Great Recession prevailing throughout this period, which threatens to destabilize the global financial system and world economy (Kousenidis et al., 2012). Notably, the strongest dependence between WTI-China occurs in P5, by which time China has become the world's largest net importer of oil, with its increased demand having a significant effect on the oil market (Financial Times, 2015). Moreover, the energy market becomes more financialized at this time, with crude oil actively used as a hedging instrument in the spot and derivative markets (Bencivenga, 2012). Lin and Tamvakis (2001) find significant spillovers between crude oil futures markets between the New York and London markets; while Kang et al. (2017) show that spillovers from other commodity markets to the oil market, as the volatility receiver, increase during the 2008 Financial Crisis. It is therefore plausible to postulate that such crude oil derivatives stimulate spillovers from the oil market, and that they, in their turn, influence stock markets during periods of extreme volatility, thus strengthening the dependence between the oil and stock markets. Taking the observations together, it is reasonable to assert that dependence between the oil and stock markets grows stronger over these periods, in response to the escalating gravity of economic conditions.

In respect of market dependence at extreme risk, the tail dependence among the three paired markets during P1 is symmetrical (Kendall's $\tau$ of upper tail = 0.04, 0.01 and NA; Kendall's $\tau$ of lower tail $=0.04,0.01$ and NA for WTI-US, WTI-China and US-China, respectively), but turns asymmetrical during P4 (upper tail $=0.03$, NA and 0.02; lower tail $=0.03,0.00$ and NA) and during P5 (upper tail $=0.19,0.10$ and NA; lower tail $=0.19,0.03$ 
and 0.04). Most noticeably, the tail dependence in P5 appears to be the strongest of the three periods, which is clear evidence showing robust market dependence associated with extreme risk in the wake of the Financial Crisis and Great Recession. Overall, these results consistently demonstrate that the oil market, whose volatility increases sharply during P4 and P5, exerts a dominant impact on the dependence relationships between the three paired markets.

Our results show that China's stock market develops into the root node in the period of P2, when the Asian financial crisis of 1997 breaks out. Since this crisis has its origin in Southeast Asia, the impact on the US market and crude oil market is transmitted ultimately through China. It appears, however, that during this phase the dependences between the three paired markets, especially WTI-China and US-China, are lower than the dependences in the periods when WTI and US stock market are the root nodes. This is arguably because China's stock market is not well integrated with the world economy after a long period of financial insularity, limiting its global influence. The dependence between the oil market and China's stock market also remains low. Notwithstanding that China's demand for oil increases during this period (Leung, et al., 2011), its dependence on this source of energy is far lower than that of the US, as much of its carbon-based power is derived from its vast coal deposits (Kumar et al., 2012). In addition, coal is significantly cheaper than oil (Chakravorty et al., 2008) and has its price controlled by the government (Chen and Lv, 2015). These observations are consistent with Figures 2 and 3, which depict a lack of volatility, confirming that the dependences between China's stock market with the oil and US stock markets are not robust. The weight of evidence suggests that China, as the root node, is a volatility receiver from the oil and US stock markets, absorbing global volatilities during this phase.

Consistent with the above observations, the tail dependence among the three markets is symmetrical (upper tail $=0.00, \mathrm{NA}$ and NA; lower tail $=0.00$, NA and NA for US-China, WTI-China and WTI-US, respectively). The tail dependence between WTI-US is close to zero and there is no tail dependence between US-China and WTI-China. These results further support the contention that when the China's stock market is the root node in P2, the impact of extreme risk on dependence between the three paired markets is limited. This is a further 
illustration that China's economy had not yet begun to exert a pervasive influence over world markets during this phase.

Further, our results show that the US stock market becomes the root node in the periods of P3 and P6. Albeit that the terrorist attack of September 11 takes place at the end of P2, it casts a long shadow over P3, generating long-term economic ramifications for the world's financial and oil markets and confirming that the US stock market is at the root of the contagion. Charles and Darné (2006), analyzing 10 daily stock market indexes, find supportive evidence that the terrorist attack and its aftermath cause large transient and permanent shocks to international stock markets. Similarly, the effects of the Afghanistan War of 2001, which occurs at the end of P2, arguably projects its influence over P3. Chossudovsky (2010) argues that a covert objective is to secure control of the country's vast, but as yet underdeveloped oil, natural gas and mineral resources, besides which this country has a strategic position standing at the crossroads of "pipeline routes and major oil and gas reserves". Therefore, it seems plausible that this geographically limited conflict would have ramifications much wider than its topographical scope, stimulating market interactions. Furthermore, the outbreak of the Iraq War of 2003 delivers an oil shock to the world economy that has a significant and far-reaching influence on world demand and supply, the effect of which is ultimately transmitted through the US market. In a similar way to Chossudovsky (ibid.), Williams (2010) suggests that the conflict is evidence of competition between the great powers of the US and China to control global oil resources. Such implicit economic rivalry must, of itself, significantly influence crude oil pricing, and this factor is likely to have a progressively greater influence as demand for energy from China and other emerging nations grows.

Further, in P6, the world economy begins to emerge from the deepest recession since the Great Depression of the 1930s. Nevertheless, although this is characterized as a period of modest, economic recovery (United Nations, 2013), extreme volatility persists for the best part of a decade, as we observe in Figure 1. Such increasing instability towards the end of the period may also have been provoked by two major events: China's stock market crash of 2016 and the OPEC decision to cut oil production (The Economic Times, 2016), intensifying 
market perceptions of risk and hence augmenting interactions among the three markets. This is supported by Kendall's $\tau(=0.05)$, which is the strongest at this point, confirming that the dependence between the US and China markets strengthens during this period. The US stock market once more plays a fundamental role, transmitting information through the medium of its powerful, global influence.

Concerning market dependence at extreme risk, the tail dependence is symmetrical in P3 (upper tail $=0.01,0.02$ and 0.01 ; lower tail $=0.01,0.02$ and 0.01 , for WTI-US, US-China and WTI-China, respectively), but turns asymmetrical in P6 (upper tail $=0.11,0.06$ and NA; lower tail $=0.03$, NA and NA, for WTI-US, US-China and WTI-China, respectively). The asymmetric tail dependence is attributable to perceived market volatility resulting from the uncertainty of the protracted process of global economic recovery, which renders these markets increasingly sensitive to the extreme risks that they face.

In summary, risk volatilities respond with great sensitivity to unfolding political and economic crises, with the strongest dependences created between the crude oil market and the US market among most of the periods observed. Dependence between the three markets, especially between WTI and China and the US and China stock markets, grows stronger and the tail dependence turns asymmetrical following the Financial Crisis and the Great Recession, presenting a strong case that significant economic and political events such as these play a decisive role in the nature of the interactions between the crude oil and world financial markets. Furthermore, information transmitted through the US node has a more powerful influence on the dependences between the markets than that transmitted through the China node. Above all, it is the crude oil market that dominates, standing at the nexus of all dependences, at most times, and transmitting economic shocks, directly and indirectly, that generate the greatest volatilities observed between the markets.

Table 4. Estimation results of the vine copula model for the three paired markets during the six structural break periods

\begin{tabular}{lllllll}
\hline & Pair-copula model & Parameter1 & Parameter2 & Kendall's $\tau$ & Upper tail & Lower tail \\
P1(2 May1991-7 Oct 1993) (node: WTI) & & & & \\
WTI-US & Student- $t$ & 0.05 & $5.86^{* * * *}$ & 0.03 & 0.04 & 0.04 \\
& & $(0.05)$ & $(1.73)$ & & \\
\hline
\end{tabular}




\begin{tabular}{lllllll}
\hline WTI-China & Student- $t$ & -0.06 & 7.49 & -0.04 & 0.01 & 0.01 \\
& & $(0.05)$ & $(2.54)$ & & & NA \\
US-China|WTI & Rotated Tawn type & -20 & 0.00 & 0.00 & NA &
\end{tabular}

P2 (7 Oct 1993-5 Nov 2002) (node: China)

$\begin{array}{lllllll}\text { US-China } & \text { Rotated BB7(90 } & -1.02^{* * * *} & -0.03 & -0.03 & \text { NA } & \text { NA } \\ \text { WTI-China } & (0.01) & (0.02) & & & \\ & \text { Rogrees) } & -1.13^{* * *} & -0.91^{* * *} & -0.04 & \text { NA } & \text { NA } \\ \text { WTI-US|China } & \text { degrees }) & (0.08) & (0.10) & & & \\ & \text { Student- } t & -0.02 & 16.42^{* * * *} & -0.01 & 0.00 & 0.00\end{array}$

P3 (5 Nov 2002-19 Oct 2006) (node: US)

\begin{tabular}{|c|c|c|c|c|c|}
\hline WTI-US & Student $-t$ & $\begin{array}{l}-0.14^{* * *} \\
(0.03)\end{array}$ & $\begin{array}{l}8.54^{* * * *} \\
(2.80)\end{array}$ & -0.09 & 0.01 \\
\hline US-China & Student $-t$ & $\begin{array}{l}0.05 \\
(0.04)\end{array}$ & $\begin{array}{l}7.81^{* * *} \\
(2.75)\end{array}$ & 0.03 & 0.02 \\
\hline WTI-China|US & Student $-t$ & $\begin{array}{l}0.03 \\
(0.04)\end{array}$ & $\begin{array}{l}8.56^{* * * *} \\
(3.02)\end{array}$ & 0.02 & 0.01 \\
\hline
\end{tabular}

P4 (19 Oct. 2006-17 Apr 2009) (node: WTI)

$\begin{array}{lllllll}\text { WTI-US } & \text { Student } t & 0.07^{*} & 6.95^{* * *} & 0.04 & 0.03 & 0.03 \\ \text { WTI-China } & & (0.04) & (2.2) & & & \\ & \text { Clayton } & 0.09^{* *} & -0.02^{* * *} & 0.04 & \text { NA } & 0.00 \\ \text { US-China|WTI } & & (0.04) & (0.00) & & & \\ & & 4.61^{*} & 5.56^{* * *} & 0.02 & 0.02 & \text { NA } \\ & & (2.37) & (1.14) & & & \end{array}$

P5 (17 Apr2009-18 Apr2013) (node: WTI)

\begin{tabular}{|c|c|c|c|c|c|c|}
\hline WTI-US & Student- $t$ & $\begin{array}{l}0.51^{* * *} \\
(0.03)\end{array}$ & $\begin{array}{l}0.2^{* * * *} \\
(0.05)\end{array}$ & 0.34 & 0.19 & 0.19 \\
\hline WTI-China & BB7 & $\begin{array}{l}1.08^{* * *} \\
(0.04)\end{array}$ & NA & 0.13 & 0.10 & 0.03 \\
\hline US-China|WTI & Survival Joe & $\begin{array}{l}1.03^{* * *} \\
(0.03)\end{array}$ & & 0.02 & NA & 0.04 \\
\hline
\end{tabular}

P6 (18 Apr2013-31 May 2016) (node: US)

\begin{tabular}{|c|c|c|c|c|c|c|}
\hline WTI-US & BB1 & $0.18^{* * *}$ & $1.09^{* * * *}$ & 0.16 & 0.11 & 0.03 \\
\hline & & $(0.07)$ & $(0.04)$ & & & \\
\hline US-China & Gumbel & $\begin{array}{l}1.05^{* * *} \\
(0.03)\end{array}$ & NA & 0.05 & 0.06 & NA \\
\hline
\end{tabular}




\begin{tabular}{lllllll}
\hline WTI-China|US & Rotated Tawn type & $1.94^{*}$ & $0.01^{* * *}$ & -0.01 & NA & NA \\
& $2(270$ degrees $)$ & $(0.99)$ & $(0.00)$ & & &
\end{tabular}

Notes. Table 4 reports the estimation results of the vine copula model for the three paired markets, WTI-US, WTI-China and US-China, during the six structural break periods based on Equation 11. Parameter 1 and Parameter 2 are two parameters used to determine the pair-copula model. The conditional paired markets are represented by a sign of $\mid$ followed by WTI, US and China to represent the oil market, US stock market and China's stock market serving as a root node. For example, US-China|WTI indicates the dependence between US and China stock markets when the oil market is the root node. The types of copula models selected for the three paired markets, based on AIC and BIC Criteria, are presented in the second column, headed 'Pair-copula model'. The values in the columns headed 'Upper tail' and 'Lower tails' represent tail dependence by Kendall's $\tau$; and NA in the column indicates that the value of tail dependence is non-existent. The values in parentheses are the standard errors. ${ }^{* * *},{ }^{* *}$ and ${ }^{*}$ indicate confidence levels at $1 \%, 5 \%$ and $10 \%$, respectively.

When the dependence that exists among markets grows stronger, significant risks are more likely to be transmitted from one market to another. We consider the nature of the transmission in the next section.

\subsection{Volatility spillovers by VAR(1)-BEKK-GARCH $(1,1)$ model: results and discussions}

We now consider volatility spillovers between the three markets during the six structural break periods. Table 5 reports the results of the conditional variance and residual, obtained from estimation of the VAR(1)-BEKK-GARCH $(1,1)$ model.

Table 5. Estimation results of the VAR-BEKK-GARCH model for the three paired markets during the six structural break periods

\begin{tabular}{|c|c|c|c|c|c|c|}
\hline & $\mathrm{P} 1$ & $\mathrm{P} 2$ & P3 & $\mathrm{P} 4$ & P5 & P6 \\
\hline \multicolumn{7}{|c|}{ Matrix C } \\
\hline $\mathrm{C}(1,1)$ & $0.0046^{* * *}$ & $-0.0012^{* * * *}$ & $-0.0010^{* * * *}$ & 0.0006 & $0.0017^{* * *}$ & $0.0026^{* * *}$ \\
\hline $\mathrm{C}(2,1)$ & 0.0001 & 0.0002 & $-0.0013^{* *}$ & $0.0096^{* * * *}$ & -0.0005 & 0.0003 \\
\hline $\mathrm{C}(2,2)$ & -0.0000 & $0.0030^{* * * *}$ & 0.0000 & 0.0000 & 0.0000 & 0.0001 \\
\hline $\mathrm{C}(3,1)$ & 0.0024 & $0.0016^{* *}$ & $-0.0046^{* * *}$ & $-0.0047^{* * *}$ & $0.0026^{*}$ & 0.0000 \\
\hline$C(3,2)$ & 0.0000 & 0.0001 & 0.0000 & -0.0000 & 0.0003 & -0.0004 \\
\hline $\mathrm{C}(3,3)$ & -0.0000 & $0.0012^{* * *}$ & 0.0000 & -0.0000 & $0.0045^{* * *}$ & 0.0000 \\
\hline \multicolumn{7}{|c|}{ Matrix D } \\
\hline $\mathrm{D}(1,1)$ & 0.0380 & $0.2577^{* * * *}$ & $0.2061^{* * *}$ & $0.2391^{* * * *}$ & $0.3336^{* * *}$ & $0.4432^{* * *}$ \\
\hline $\mathrm{D}(1,2)$ & -0.0244 & -0.0218 & -0.0539 & $-0.1862^{* * *}$ & $-0.0122^{* * *}$ & $0.1759^{* * *}$ \\
\hline $\mathrm{D}(1,3)$ & 0.0523 & $-0.1550^{* * * *}$ & $-0.3473^{* * *}$ & $-0.1786^{* *}$ & -0.0566 & 0.0791 \\
\hline $\mathrm{D}(2,1)$ & 0.0132 & 0.0065 & $0.0371^{* *}$ & 0.0009 & -0.0198 & -0.0455 \\
\hline $\mathrm{D}(2,2)$ & $1.1071^{* * *}$ & $0.4455^{* * *}$ & $0.1732^{* * *}$ & $0.1987^{* * *}$ & $-0.1075^{* * *}$ & $0.1746^{* * *}$ \\
\hline $\mathrm{D}(2,3)$ & $0.0435^{* *}$ & $-0.0252^{* *}$ & $0.0898^{*}$ & $-0.0791^{* *}$ & $-0.1006^{*}$ & $0.1165^{* * *}$ \\
\hline $\mathrm{D}(3,1)$ & $0.0713^{* *}$ & -0.0064 & $0.0252^{* *}$ & $0.0612^{* * *}$ & 0.0225 & 0.0132 \\
\hline
\end{tabular}




\begin{tabular}{|c|c|c|c|c|c|c|}
\hline $\mathrm{D}(3,2)$ & $-0.1115^{* * * *}$ & $-0.0203^{* *}$ & $-0.0647^{* * *}$ & $0.0939^{* * *}$ & 0.0237 & $-0.0898^{* * * *}$ \\
\hline $\mathrm{D}(3,3)$ & $0.3375^{* * *}$ & $0.1156^{* * *}$ & $0.0643^{* *}$ & $0.1765^{* * *}$ & $0.2833^{* * *}$ & $0.1911^{* * *}$ \\
\hline \multicolumn{7}{|c|}{ Matrix A } \\
\hline $\mathrm{A}(1,1)$ & -0.2205 & $0.9622^{* * *}$ & $0.9334^{* * *}$ & $0.9666^{* * *}$ & $0.9490^{* * *}$ & $0.8273^{* * *}$ \\
\hline $\mathrm{A}(1,2)$ & $-0.1032^{*}$ & 0.0046 & $-0.3460^{*}$ & 0.0333 & 0.0974 & -0.1021 \\
\hline $\mathrm{A}(1,3)$ & $1.8150^{* * * *}$ & $0.0447^{* * *}$ & 0.0940 & $0.1189^{* * *}$ & $0.1120^{* *}$ & $-0.0342^{* * * *}$ \\
\hline $\mathrm{A}(2,1)$ & -0.0015 & $-0.0030^{* *}$ & $-0.1357^{* *}$ & -0.0117 & $-0.1077^{* *}$ & $0.0159^{* * *}$ \\
\hline $\mathrm{A}(2,2)$ & $-0.7341^{* * * *}$ & $0.9130^{* * * *}$ & $-0.9281^{* * * *}$ & $0.8895^{* * *}$ & $-1.0164^{* * * *}$ & $0.9778^{* * *}$ \\
\hline $\mathrm{A}(2,3)$ & 0.0009 & $0.0069^{* *}$ & -0.3317 & $0.1069^{* * *}$ & -0.2305 & $-0.0373^{* * *}$ \\
\hline $\mathrm{A}(3,1)$ & $-0.3489^{* * *}$ & 0.0027 & $-0.0322^{* * * *}$ & $-0.0227^{* * *}$ & -0.0145 & $0.0010^{* * *}$ \\
\hline $\mathrm{A}(3,2)$ & -0.0685 & 0.0025 & -0.1040 & $-0.0229^{* * *}$ & $0.1627^{*}$ & $0.0293^{* * *}$ \\
\hline $\mathrm{A}(3,3)$ & -0.1993 & $0.9874^{* * *}$ & $0.9545^{* * *}$ & $0.9468^{* * *}$ & $0.9183^{* * *}$ & $0.9791^{* * * *}$ \\
\hline
\end{tabular}

Notes. Table 5 reports the estimation results of the conditional variance for the three paired markets, WTI-US, WTI-China and US-China, during the six structural break periods based on the VAR(1)-BEKK-GARCH $(1,1)$ model. The numbers, 1, 2 and 3, in the parentheses represent the US stock market, China's stock market and oil market, respectively. A, D and C are the parameter matrix of residual, conditional and constant as specified in Equation 14, respectively. ${ }^{* * *},{ }^{* *}$ and ${ }^{*}$ indicate confidence levels at $1 \%, 5 \%$ and $10 \%$, respectively.

In Table 5, D $(1,2)$ indicates that the conditional variance of China's stock market affects the US stock market. A $(1,2)$ indicates that the residual of China's stock market affects the US stock market. When a spillover occurs, it is either unidirectional from market $i$ to market $j$, and vice versa; or bidirectional between market $i$ and market $j$. The rejection of the null hypothesis for two tests, i.e., $\mathrm{A}(i, j)=\mathrm{D}(i, j)=0$, and $\mathrm{A}(j, i)=\mathrm{D}(j, i)=0$, indicates that the spillover between market $i$ and market $j$ is bidirectional. The rejection of the null hypothesis of either of the two tests indicates that the spillover is unidirectional. The results show that the coefficients of the conditional variance and residual during the six periods are significant, at most times, at $1 \%, 5 \%$ and $10 \%$ significance levels, which indicates that the spillovers between the three paired markets occur. But, the direction of the spillovers will be determined by the Wald test. The results of the Wald test are shown in Table 6.

Table 6. Wald test of volatility spillovers between the three paired markets during the six structural break periods

\begin{tabular}{llll}
\hline & WTI & US & China \\
\hline P1(2 May1991-7 Oct 1993) (node: WTI) & & & \\
Spillover from WTI to & & $122.9002(0.0000)^{* * * *}$ & $2.7253(0.0655)^{*}$ \\
Spillover from US to & $30.4986(0.0000)^{* * *}$ & & $1.0628(0.3455)$ \\
\hline
\end{tabular}


P2 (7 Oct 1993-5 Nov 2002) (node: China)

Spillover from WTI to

Spillover from US to

Spillover from China to

P3 (5 Nov 2002-19 Oct 2006) (node: US)

Spillover from WTI to

Spillover from US to

Spillover from China to

P4 (19 Oct 2006-17 Apr 2009) (node: WTI)

Spillover from WTI to

Spillover from US to

Spillover from China to

P5 (17 Apr 2009-18 Apr 2013) (node: WTI)

Spillover from WTI to

Spillover from US to

Spillover from China to

P6 (18 Apr 2013-31 May 2016) (node: US)

Spillover from WTI to

Spillover from US to

$5.2570(0.0052)^{* * *}$

Spillover from China to

$0.7020(0.4956)$

$2.2317(0.1073)$

$6.8859(0.0010)^{* * * *}$
$5.2036(0.0055)^{* * *}$

$0.8348(0.4339)$

1.8545(0.1565)

$13.9925(0.0000)^{\text {*** }}$

$9.5308(0.0000)^{* * *}$

$2.2922(0.1010)$

$9.9709(0.0000)^{* * * *}$

$9.5660(0.0000)$ ***

1.1587(0.3139)

$3.5492(0.0287)^{* *}$

$3.8891(0.0205)^{* *}$

$2.5700(0.0765)^{*}$

2.9424(0.0527)

1.1093(0.3298)

Notes. Table 6 reports the results of Wald test for volatility spillovers between the three paired markets, WTI-US, WTI-China and US-China, during the six structural break periods. The statistics reported are standard error. P values are in the parentheses. The null hypothesis of the Wald test is that there is no spillover effect. ${ }^{* * *},{ }^{* *}$ and ${ }^{*}$ indicate confidence levels at $1 \%, 5 \%$ and $10 \%$, respectively.

Our results demonstrate that during the P1 period (root node: WTI), the spillovers between WTI and the US stock market are bidirectional (standard error=30.4986, $\mathrm{P}=0.0000$; 122.9002, $\mathrm{P}=0.0000)$, as they are between WTI and China's stock market $(2.7253, \mathrm{P}=0.0655$; 8.8154, $\mathrm{P}=0.0001$ ). The oil market, as the root node, performs its transmitting role in this multi-market dependence. During the P1 period, the Gulf War breaks out, generating a substantial shock to the supply of, and demand for, crude oil, so that aggregated oil shocks subsequently have a destabilizing impact on global markets, as suggested by Barsky and Kilian (2004). Our results are consistent with empirical evidence that the volatility of the oil price affects stock returns, with risk from the oil market transmitted to the stock market (Park 
and Ratti, 2008; Jammazi, 2014). Kilian and Park (2009) provide further evidence that the oil price has a significant effect on the US stock price. Further, our results show that the oil market is also affected by stock market movements, which is supported by Malik and Hammoudeh (2007), who find significant spillovers from the stock market to the oil market. However, there is no evidence to suggest the incidence of spillovers between the US and China's stock markets. This is arguably because the two markets demonstrate little interconnectedness during this phase, as evidenced in Table 4. China's stock market is established only at the end of 1991, after a long period of economic isolation. Since its trading and securities regulatory systems are at a formative stage, with quoted companies extensively controlled by the state or state-appointed nominees (Liu, et al., 2016; Liu, et al., 2018), inward investment and interactions with international markets are limited. Overall, the evidence suggests that the crude oil market takes a central position in the global economy during this period.

During the P2 period (root node: China), risk volatilities spill over from the oil market to the two stock markets, and from the US stock market to China's stock market. Such risk volatilities are, debatably, stimulated first by the attack of September $11^{\text {th }}$, and next by the outbreak of the Afghanistan War in October. It is evident that the terrorist attack causes the Dow Jones index to fall over 600 points, deepening the 2001 recession (the balance, 2018), and also the oil price by 35\% (Oilprice.com, 2009). These adversities are further exacerbated by the subsequent US attack on Afghanistan in October 2001. Consequential turbulence in the oil market spills over into both the US (16.1981, $\mathrm{P}=0.0000)$ and China $(2.8418, \mathrm{P}=0.0583)$ stock markets, providing further evidence that the oil market exerts an extensive, fundamental influence on financial trading. Resulting from the trajectories of spillovers between these markets, the volatility of the US stock market is transmitted to China's stock market (2.3435, $\mathrm{P}=0.0960$ ), indicating that the movements of the former have begun to have an effect on China's market movements. There is no spillover, however, from China's stock market to the oil market, nor to the US stock market. This is further evidence that China's stock market has not fully integrated into the world economy and developed a global influence. Thus, when the Asian financial crisis struck in 1998, risks from the oil market and international stock markets 
were far less likely to be deflected or repelled by China's stock market; instead, risks from the oil and international stock markets were more likely to be transmitted to China's stock market, which acted as a volatility receiver rather than transmitter, as explained in 4.4 above.

During the P3 period (root node: US stock market), spillovers between the oil market and US stock market are bidirectional (6.8859, $\mathrm{P}=0.0010$; 9.5308, $\mathrm{P}=0.0000)$. But the risk spills only from the US stock market to China's stock market (3.0809, P=0.0459), and from China's stock market to the oil market (5.2036, $\mathrm{P}=0.0055)$. During this period, the Iraq War breaks out, increasing the markets' perception of risk, and exerting an immediate spillover effect onto the US stock market; and, as is also likely, onto other sectors of the global economy. Moreover, the September $11^{\text {th }}$ attack at the end of the P2 period causes a moderate recession in the US that continues into P3, depressing its demand for crude oil and having an inhibiting effect on China's stock market and other markets besides. Mehrara (2007) finds that the oil and US stock markets act, respectively, as originators and transmitters of risk volatility, fundamentally affecting the world's economy and leading it into both contraction and growth. Our P3 analysis of how risk volatilities stem from successive crises, spilling over from the oil market to the US and China stock markets, as well as into other world markets, tends to support this thesis. In addition, our results show that risk is transmitted from China's stock market to the oil market during the P3 period. With China's inexorable ascent in the world economy, its slowly burgeoning stock market is beginning to exert an influence and leverage over the global oil market. Simultaneously, the special adjustment mechanism for oil pricing in China, first adopted during this period, may have also affected aggregate demand and supply in the international oil market (Chen and Lv, 2015), influencing international oil pricing and investment portfolios (Chai et al., 2011).

During the P4 period (root node: WTI), the spillovers between the oil market and the US stock market are bidirectional (13.9925, $\mathrm{P}=0.0000 ; 9.9709, \mathrm{P}=0.0000)$, the same as between the oil market and China's stock market (9.5660, $\mathrm{P}=0.0000 ; 5.3764, \mathrm{P}=0.0046)$. In 2007, when the Financial Crisis starts in the US, the risks stemming from one of the greatest fiscal catastrophes in history are rapidly transmitted from one market to the next, causing a series of market crashes commencing with a massive fall in the Dow-Jones index (the Balance, 2018), 
provoking a global economic recession and depressing the aggregate demand for crude oil, which, in turn, WTI promptly transmits to the US and China stock markets. Wen et al (2012) examine the dependence between China's stock market and the oil market and find that it rises significantly during the crisis, supporting our postulation that spillovers spread swiftly to China, because of its increasing integration with external markets. It is worth noting that risk unidirectionally spills over from China's stock market to the US stock market (3.5492, $\mathrm{P}=0.0287$ ), suggesting that the US stock market is extremely sensitive during the crisis period. The US stock market, undermined by its home-grown financial crisis, is assailed by the risk from other markets.

During the P5 period (root node: WTI), the oil market generates a unidirectional spillover effect on the US and China's stock markets (2.5700, $\mathrm{P}=0.0765 ; 3.8891, \mathrm{P}=0.0205)$. This is clear evidence that oil exerts a decisive influence in shaping stock market movements, acting as a point of entry for spillovers when the world economy has plunged into the recession. This is consistent with Table 4, which shows the strongest dependence between WTI-US and WTI-China, with the highest Kendall's $\tau$ at 0.34 and 0.13 of all the periods observed. Kang et al (2015) find that the oil market affects stock markets more significantly after the Financial Crisis of 2007-08 than before. Awartani and Maghyereh (2013) also assert that the oil market plays a significant role in the information transmission mechanism after the crisis, spreading risk to stock markets. Furthermore, the risk in the US stock market is transmitted to China's stock market unidirectionally (2.9424, $\mathrm{P}=0.0527)$. The US stock market has become extremely volatile in the aftermath of its domestic financial catastrophe, and this volatility quickly spills over into other markets, China's included, on an unprecedented scale.

During the P6 period (when the root note is the US), the volatilities spill from the US stock market to the oil market unidirectionally (5.2570, $\mathrm{P}=0.0052)$, while the spillovers between WTI-China (11.0374, $\mathrm{P}=0.0000 ; 23.7262, \mathrm{P}=0.0000)$ and US-China (3.7520, $\mathrm{P}=0.0235 ; 6.1718, \mathrm{P}=0.0021)$ are bidirectional. These observations are convincing evidence to indicate that the volatility of stock markets dominates the global economy during the protracted period of economic recovery, with the US being the nexus of transmission. The US and China stock markets exert a powerful influence during this period, given that they are the 
world's two biggest economies. Following the crisis, the US stimulates its own economy despite tighter global fiscal conditions, supporting the financial sector in its efforts to weather the harsh economic climate and begin modest regeneration. China, as a rising economic power, and by dint of its continuing growth, helps to drive the revival of the global economy. Moreover, the dependence between the two stock markets has grown stronger than ever, as evidenced in Table 4 (Kendall's $\tau=0.05$ ), so that the risks inherent within these two markets will, thus, have an escalating effect on the crude oil market (2.8418, $\mathrm{P}=0.0583)$. China's interactions with the oil market and US market signifies that its economy is, by this period, more fully integrated into the world economy, and that economic globalization, and the degree of China's economic expansion, have helped to determine the nature of market risk transmission.

Overall, our analyses demonstrate that the risk spillovers prevailing in each period change in step with dynamic dependences and interactions between the markets. These changes respond to the influence from major economic and political events, causing market uncertainty and volatilities to spread and intensify. Most significantly, though, our analyses appear to detect an increasing strength in the influence of China on the world's economy, with its growing economic power appearing to strengthen the financial signals that it transmits. As we have already noted in our Introduction, China's integration into global trading and the increasing strength of its stock market suggest that it is beginning to influence world oil and stock markets.

\section{Conclusions}

Our study, for the first time, integrates the copula models and the multivariate GARCH model to analyze the dependence and spillovers between the oil market (WTI) and the US and China stock markets over the extended period of 1991-2016. We first analyze the dynamic dependence relationship between the three paired markets, i.e., WTI-US, WTI-China and US-China, using the time-varying copula model. We further conduct an analysis of structural breaks of market dependence between the paired markets, and incorporate the structural breaks into an analysis of the market dependences by applying the vine copula model, and 
determine the direction of risk transmission between the markets by applying the trivariate VAR-BEKK-GARCH model. We draw three conclusions.

First, dependences between the oil market and the stock markets are shaped by the impact of political and economic manifestations, which have a decisive effect on the nature of the interactions between them. This is demonstrated by the evidence that their dependences grow stronger during and after the Financial Crisis of 2007-08, and the tail dependence simultaneously turns asymmetric. Different markets act as the root nodes across the temporal subdivisions defined by the structural breaks, receiving and transmitting risk volatilities from and to the other markets and wielding varying degrees of influence over the market dependences. The oil market, in particular, stands at the nexus of the dependences, acting upon them to stimulate rapid and continual fluctuations. This effect manifests itself most acutely in the aftermath of the Financial Crisis, demonstrating the increasing interdependence of the oil and financial markets. Second, distinctive risk volatilities spill over between the markets, with varying directionality, activated by a series of significant economic and political events across the six structural break periods. The trajectories of these spillovers change direction across the temporal subdivisions, shaped by the strength of market dependence and interactions, which are, in their turn, modified by major changes of a political or economic nature. Crude oil is the strongest transmitter of all three, shaping the direction of volatilities between the markets. Third, and perhaps most interestingly of all, our analysis reveals that world economic power may now be in the midst of a transformation. The massive destabilization provoked by the Financial Crisis comes at the same time as China's burgeoning economic power and massive increase in domestic energy consumption (caused, in large part, by a growth in the private motoring sector), and development of trade initiatives such as One-Belt-One-Road initiative initiated in 2013 (Du and Zhang, 2018), have transformed it into the largest oil importer in the world (Financial Times, 2015). The results of our study suggest that China has now become a transmitter of volatility spillovers itself and a significant participant in the sphere of globalization. Our analysis thus provides evidence of the growing power of China's economy in relation to the US, suggesting the advent of global economic rebalancing. 
Our research will help to improve regulation and practice. From the perspective of policy, our estimation procedure will enable governments and regulators to analyze and predict the formerly unforeseeable consequences of dynamic market interactions, facilitating the development of long-term policies to achieve consistent and sustainable growth. This is particularly important at a time when Middle Eastern conflicts, economic and financial market turmoil, and problematical attempts to ameliorate the effects of global warming are impacting unpredictably on the trajectories of world oil prices and financial markets. Moreover, the evaluation procedure that we have developed can be applied to examine similar phenomena in other countries and contexts and in different combinations. From the perspective of practice, our research provides an analytical procedure for investors and market-makers alike, enabling them to optimize their portfolios and minimize investment risk, especially during a period of intensifying global volatility. More importantly, our identification of China as an increasingly powerful transmitter of market information offers analysts an insight into similar phenomena in respect of other emerging economies.

\section{Acknowledgments}

This work was partially supported by grants from the Key Program of National Natural Science Foundation of China (NSFC nos. 71433001, 71631005 and 71671013), the National Program for Support of Top-Notch Young Professionals, Beijing Advanced Innovation Center for Soft Matter Science and Engineering, Humanities and Social Sciences Youth Foundation of Ministry of Education of China (No. 16YJC790026). 


\section{References}

Aas, K., Czado, C., Frigessi, A., Bakken, H. (2009). Pair-copula constructions of multiple dependence. Insurance: Mathematics and economics, 44(2), 182-198.

Allen, D.E., Ashraf, M. A., McAleer, M., Powell, R. J., Singh, A. K. (2013). Financial dependence analysis: applications of vine copulas. Statistica Neerlandica, 67(4), 403-435.

Aloui, R., Aïssa, M. S. B. (2016). Relationship between oil, stock prices and exchange rates: a vine copula based GARCH method. North American Journal of Economics \& Finance, 37, 458-471.

Aloui, R., Hammoudeh, S., Nguyen, D. K. (2013). A time-varying copula approach to oil and stock market dependence: The case of transition economies. Energy Economics, 39, 208-221.

Antonakakis, N., Filis, G. (2013). Oil prices and stock market correlation: a time-varying approach. International Journal of Energy and Statistics, 1(01), 17-29.

Arouri, M. E. H., Lahiani, A., Bellalah, M. (2010). Oil price shocks and stock market returns in oil-exporting countries: the case of GCC countries. International Journal of Economics and Finance, 2(5), 132-139.

Avdulaj, K., Barunik, J. (2015). Are benefits from oil-stocks diversification gone? New evidence from a dynamic copula and high frequency data. Energy Economics, 51, 31-44.

Awartani, B., Maghyereh, A. I. (2013). Dynamic spillovers between oil and stock markets in the Gulf Cooperation Council Countries. Energy Economics, 36, 28-42.

Bai, J., Perron, P. (1998). Estimating and testing linear models with multiple structural changes. Econometrica, 66(1), 47-78.

Bai, S., Kai, S. K. (2018). Oil prices, stock returns, and exchange rates: empirical evidence from China and the United States. North American Journal of Economics \& Finance, 44, https://doi.org/10.1016/j.najef.2017.10.013.

Barsky, R. , Kilian, L. (2004). Oil and the macroeconomy since the 1970s. Journal of Economic Perspectives, 18(4), 115-134.

Bauwens, L., Lubrano, M. (2002). Bayesian option pricing using asymmetric GARCH models. Journal of Empirical Finance, 9(3), 321-342.

Bekiros, S. D., Diks, C. G. H. (2008). The relationship between crude oil spot and futures prices: cointegration, linear and nonlinear causality. Energy Economics, 30(5), 2673-2685.

Bekiros, S., Uddin, G. S. (2017). Extreme dependence under uncertainty: an application to stock, currency and oil markets. International Review of Finance, 17(1), 155-162.

Bencivenga, C. (2012). Oil prices and the financial crisis. Review of Managerial Science, 6(3), 227-238.

Bhar, R., Malliaris, A. G. (2011). Oil prices and the impact of the financial crisis of 2007-2009. Energy Economics, 33(6), 1049-1054.

Bjørnland, H. C. (2009). Oil price shocks and stock market booms in an oil exporting country. Scottish Journal of Political Economy, 56(2), 232-254.

Brechmann, E. C., Czado, C., Kurowicka, D. (2013). Selecting and estimating regular vine copula and application to financial returns. Computational Statistics \& Data Analysis, 59(1), 52-69.

Brechmann, E. C., Hendrich, K., Czado, C. (2013). Conditional copula simulation for systemic risk 
stress testing. Insurance: Mathematics and Economics, 53(3), 722-732.

Broadstock, D. C., Filis, G. (2014). Oil price shocks and stock market returns: new evidence from the United States and China. Journal of International Financial Markets Institutions \& Money, 33(33), 417-433.

Carpantier, J. F., Samkharadze, B. (2013). The asymmetric commodity inventory effect on the optimal hedge ratio. Journal of Futures Markets, 33(9), 868-888.

Carrion-I-Silvestre, J. L. (2005). Health care expenditure and GDP: are they broken stationary? Journal of Health Economics, 24(5), 839-854.

Chai, J., Guo, J. E., Meng, L., Wang, S. Y. (2011). Exploring the core factors and its dynamic effects on oil price: an application on path analysis and BVAR-TVP model. Energy Policy, 39(12), 8022-8036.

Chakravorty, U., Moreaux, M., Tidball, M. (2008). Ordering the extraction of polluting nonrenewable resources. American Economic Review, 98(3), 1128-1144.

Charles, A., Darné, O. (2006). Large shocks and the September 11th terrorist attacks on international stock markets. Economic Modelling, 23(4), 683-698.

Charpentier, A., Segers, J. (2007). Lower tail dependence for Archimedean copulas: characterizations and pitfalls. Insurance Mathematics and Economics, 40(3), 525-532.

Chen, Q., Lv, X. (2015). The extreme-value dependence between the crude oil price and Chinese stock markets. International Review of Economics \& Finance, 39, 121-132.

Chossudovsky, Michel. (2010). “The War is Worth Waging”: Afghanistan's Vast Reserves of Minerals and Natural Gas. Global Research.

https://www.globalresearch.ca/the-war-is-worth-waging-afghanistan-s-vast-reserves-of-minerals-a nd-natural-gas/19769.

Christoffersen, P., Errunza, V., Jacobs, K., Langlois, H. (2012). Is the potential for international diversification disappearing? A dynamic copula approach. The Review of Financial Studies, 25(12), 3711-3751.

Chuang, I. Y., Lu, J. R., Tswei, K. (2007). Interdependence of international equity variances: evidence from East Asian markets. Emerging Markets Review, 8(4), 311-327.

Clayton, D. G. (1978). A model for association in bivariate life tables and its application in epidemiological studies of familial tendency in chronic disease incidence. Biometrika, 141-151.

Du, L., He, Y. (2015). Extreme risk spillovers between crude oil and stock markets. Energy Economics, $51,455-465$.

$\mathrm{Du}$, J, Zhang, Y. (2018). Does one belt one road strategy promote Chinese overseas direct investment? China Economic Review, 47. 10.1016/j.chieco.2017.05.010.

Engle, R. F., Kroner, K. F. (1995). Multivariate simultaneous generalized ARCH. Econometric theory, 11(01), 122-150.

Fan, Y., Zhang, Y. J., Tsai, H. T., Wei, Y. M. (2008). Estimating 'value at risk' of crude oil price and its spillover effect using the GED-GARCH approach. Energy Economics, 30(6), 3156-3171.

Filis, G., Degiannakis, S., Floros, C. (2011). Dynamic correlation between stock market and oil prices: The case of oil-importing and oil-exporting countries. International Review of Financial Analysis, 20(3), 152-164. 
Financial Times. (2015). China oil imports surpass those of US. https://www.ft.com/content/342b3a2e-f5a7-11e4-bc6d-00144feab7de.

Ghose, D., Kroner, K. F. (1995). The relationship between GARCH and symmetric stable processes: finding the source of fat tails in financial data. Journal of Empirical Finance, 2(3), 225-251.

Hamilton, J. D. (2009). Understanding crude oil prices. Energy Journal, 30, 179-206.

Jammazi, R. (2014). Oil shock transmission to stock market returns: wavelet-multivariate Markov switching GARCH approach. Energy, 37(1), 430-454.

Jayasinghe, P., Tsui, A. K., Zhang, Z. (2014). New estimates of time-varying currency betas: A trivariate BEKK approach. Economic Modelling, 42, 128-139.

Ji, Q., Liu, B. Y., Zhao, W. L., Fan, Y. (2018). Modelling dynamic dependence and risk spillover between all oil price shocks and stock market returns in the BRICS. International Review of Financial Analysis. https://doi.org/10.1016/j.irfa.2018.08.002.

Jiang, X., Lu, X., Xu, J. (2018). How do interregional spillovers influence the distribution of technology? The case of Chinese manufacturing. Economic Systems Research, 30(2), 1-19.

Joe, H. (1997). Multivariate models and multivariate dependence concepts. CRC Press, London.

Joe, H., Li, H., Nikoloulopoulos, A. K. (2010). Tail dependence functions and vine copulas. Journal of Multivariate Analysis, 101(1), 252-270.

Jouini, J. (2013). Return and volatility interaction between oil prices and stock markets in Saudi Arabia. Journal of Policy Modeling, 35(6), 1124-1144.

Kang, S. H., R. McIver, S. M. Yoon. (2017). Dynamic spillover effects among crude oil, precious metal, and agricultural commodity futures markets. Energy Economics, 62, 19-32.

Kang, W., Ratti, R. A., Yoon, K. H. (2015). The impact of oil price shocks on the stock market return and volatility relationship. Journal of International Financial Markets Institutions \& Money, 34, 41-54.

Kilian, L., Park, C. (2009). The impact of oil price shocks on the US stock market. International Economic Review, 50(4), 1267-1287.

Kousenidis, D. V., Ladas, A. C., Negakis, C. I. (2013). The effects of the European debt crisis on earnings quality. International Review of Financial Analysis, 30(4), 351-362.

Kraus, D., Czado, C. (2017). D-vine copula based quantile regression. Computational Statistics \& Data Analysis, 110, 1-18.

Kumar, S., Managi, S., Matsuda, A. (2012). Stock prices of clean energy firms, oil and carbon markets: a vector autoregressive analysis. Energy Economics, 34(1), 215-226.

Lee, C. C., Zeng, J. H. (2011). The impact of oil price shocks on stock market activities: Asymmetric effect with quantile regression. Mathematics and Computers in Simulation, 81(9), 1910-1920.

Leung, G.C.K., Li, R., Low, M. (2011).Transitions in China's oil economy. Eurasian Geography and Economics, 52(4), 483-500.

Lin, S. X., Tamvakis, M. N. (2001). Spillover effects in energy futures markets. Energy Economics, 23 (1), 43-56.

Liu, J., Akbar, S., Shah, Z., Zhang, D., Pang, D. (2016). Market reactions to seasoned offerings in China. Journal of Business Finance and Accounting, 43 (5-6), 597-653. 
Liu. J; Wu, Y. L, Ye, Q., Zhang, D. Y. (2018). Do seasoned offerings improve the performance of issuing firms? Evidence from China. International Review of Financial Analysis, https://doi.org/10.1016/j.irfa.2018.08.001.

Liu, B. Y., Ji, Q., Fan, Y. (2017). Dynamic return-volatility dependence and risk measure of CoVaR in the oil market: a time-varying mixed copula model. Energy Economics, 68,53-65.

Malik, F., Hammoudeh, S. (2007). Shock and volatility transmission in the oil, us and Gulf equity markets. International Review of Economics \& Finance, 16(3), 357-368.

Mehrara, M. (2007). Energy consumption and economic growth: the case of oil exporting countries. Energy Policy, 35(5), 2939-2945.

Mensi, W., Hammoudeh, S., Nguyen, D. K., Yoon, S. M. (2014). Dynamic spillovers among major energy and cereal commodity prices. Energy Economics, 43, 225-243.

Naifar, N., Dohaiman, M. S. A. (2013). Nonlinear analysis among crude oil prices, stock markets' return and macroeconomic variables. International Review of Economics \& Finance, 27(C), 416-431.

Nguyen, C. C., Bhatti, M. I. (2012). Copula model dependency between oil prices and stock markets: evidence from china and Vietnam. Journal of International Financial Markets Institutions \& Money, 22(4), 758-773.

Oilprice.com. (2009). A Recent History of Oil Prices! And Causes of the Violent Movements.

https://oilprice.com/Energy/Oil-Prices/A-Recent-History-Of-Oil-Prices-And-Causes-Of-The-ViolentMovements.html. Accessed $12^{\text {th }}$ November, 2018.

Park, J., Ratti, R. A. (2008). Oil price shocks and stock markets in the US and 13 European countries. Energy Economics, 30(5), 2587-2608.

Patton, A. J. (2006). Modelling asymmetric exchange rate dependence. International economic review, $47(2), 527-556$.

Prodan, R. (2008). Potential pitfalls in determining multiple structural changes with an application to purchasing power parity. Journal of Business \& Economic Statistics, 26(1), 50-65.

Reboredo, J. C. (2015). Is there dependence and systemic risk between oil and renewable energy stock prices? Energy Economics, 48, 32-45.

Sadorsky, P. (2012). Correlations and volatility spillovers between oil prices and the stock prices of clean energy and technology companies. Energy Economics, 34(1), 248-255.

Salisu, A. A., Mobolaji, H. (2013). Modeling returns and volatility transmission between oil price and US-Nigeria exchange rate. Energy Economics, 39(3), 169-176.

Schreiber, I., Müller, G. (2012). Equities, credits and volatilities: a multivariate analysis of the European market during the sub-prime crisis. International Review of Financial Analysis, 24(3), $57-65$.

Silvapulle, P., Smyth, R., Zhang, X., Fenech, J. P. (2017). Nonparametric panel data model for crude oil and stock market prices in net oil importing countries. Energy Economics, 67, 255-267.

Stelzer, R. (2008). On the relation between the VEC and BEKK multivariate GARCH models. Econometric Theory, 24(4), 1131-1136.

Sukcharoen, K., Zohrabyan, T., Leatham, D., Wu, X. (2014). Interdependence of oil prices and stock market indices: a copula approach. Energy Economics, 44(C), 331-339. 
The balance. (2018).

https://www.thebalance.com/how-the-9-11-attacks-still-affect-the-economy-today-3305536.

Tsuji, C. (2018). Return transmission and asymmetric volatility spillovers between oil futures and oil equities: new DCC-MEGARCH analyses. Economic Modelling, 74, 167-185.

UN Department of Economic and Social Affairs. (2013). http://www.un.org/en/development/desa/publications/wesp2013.html. Accessed 28 October, 2018.

Wang, Y., Wu, C., Yang, L. (2013). Oil price shocks and stock market activities: Evidence from oil-importing and oil-exporting countries. Journal of Comparative Economics, 41(4), 1220-1239.

Weiß, G. N., Supper, H. (2013). Forecasting liquidity-adjusted intraday Value-at-Risk with vine copulas. Journal of Banking \& Finance, 37(9), 3334-3350.

Wen, X., Wei, Y., Huang, D. (2012). Measuring contagion between energy market and stock market during financial crisis: a copula approach. Energy Economics, 34(5), 1435-1446.

Williams, P. A. (2006). Projections for the geopolitical economy of oil after war in Iraq. Futures, 38(9), 1074-1088.

Zhang, B., Wang, P. (2014). Return and volatility spillovers between China and world oil markets. Economic Modelling, 42, 413-420.

Zhang, D. (2017). Oil shocks and stock markets revisited: measuring connectedness from a global perspective. Energy Economics, 62, 323-333.

Zhu, H. M., Li, R., Li, S. (2014). Modelling dynamic dependence between crude oil prices and Asia-Pacific stock market returns. International Review of Economics \& Finance, 29, 208-223. 